industry which Prof. Barnard used to illustrate his points. Problems of design, of economy, of production and of specification all come within the ambit of this subject. It is sometimes argued by theoreticians that, in assembly, tolerances of assembled units should not be taken as simply additive, since the extremes rarely fall to be assembled together. Prof. Barnard's industrial experience, however, leads him to believe that, under certain conditions of production which not infrequently occur, such a result may, in fact, be approximately true. His point is that an investigation into the process curve (the frequency distribution of what is actually being produced) will provide the information needed to decide whether random assembly can satisfy the tolerances demanded in a particular case. He also dealt with the choice of number of classes, the importance of long runs, and the advantages of multiple selective assembly (choice of classes to be assembled) where tolerances permit.

D. J. Desmond (University of Birmingham) brought new light to bear on the craft of time-study in his paper "The Statistical Approach to Time-Study". This was based on an earlier paper to Section G of the British Association for the Advancement of Science which has been fully reported in Engineering. It is a matter of opinion whether it is necessary, as he has done, to pander to the existing nomenclature to the extent of using a term 'reciprate' for the reciprocal of the rate, but it cannot be denied that the clear light of statistical method will do much to remove the causes of the criticism that has been directed at the science of work-study.

Also in the programme for September 30 was an account by Dr. H. Ingram (Wool Research Association) of productivity measurement in the United States. Dr. Ingram had been a member of the West European team which had worked at the Bureau of Labour Statistics. His remarks aroused great interest, which seemed to belie his general theme concerning the relative interest aroused by the subject in the two countries. His matter-of-fact conclusion was that there are two immediate tasks which, if undertaken, might yield much fruit and prove more profitable than much current argument as to the meaning of productivity. These two tasks are, first, the collection of data on overall output and labour, and second, detailed comparison among firms of various important aspects of a business, such as labour turnover and costing. Even though no theoretical standards were developed, the mere knowledge of these comparisons would lead to the eradication of much inefficiency.

On October 1 Dr. E. A. G. Knowles (University of Birmingham) and Miss C. Roseman (British Nylon Spinners) gave an interesting account of methods they have used for presenting the results of an analysis of variance to those concerned with production. It is rare to find, as here, a well-designed experiment carried out under production conditions. The difficulties usually appear insuperable to the production side, but these newcomers to British industries seem to have found the way. It was the special purpose of the paper to show how the various causes of variability can be exhibited in a manner analogous to the usual control chart; it was equally valuable in showing that, with planning, such experiments on plant actually in production can not only be carried out but also understood by all concerned.

E. D. van Rest (National Physical Laboratory) brought to his audience some little-known results on the problem of deciding how many operators should attend a bank of machines. The drive for redeployment of labour has brought this problem very much to the fore in the past few years. While solutions are available for the corresponding problem of telephone traffic, these are not directly applicable to the problem of one 'piecer' looking after many spindles. If one worker is given too many to look after, some will stay idle, while if too few, his time is not fully occupied. The problem is by no means limited to this field. Mr. Rest directed attention to the ubiquity of the problem and to the methods of solution available, including analogue machines and punched-card methods. For the particular case of a few machines (up to twenty) he was able to present a series of graphs based on the work of $D$. Westgarth (University College, London, and Institute of Rubber Research, Kuala Lumpur).

The last afternoon of the conference was devoted to a discussion on the proposed Industrial Section of the International Institute of Statistics and to channels of publication for such papers as the conference had evoked. G. H. Jowett, as secretary of the Sheffield Group and chairman of the Organizing Committee, wound up the conference, paying tribute to the University of Sheffield, which had been most generous in the provision of facilities for the whole conference.

The Society intends to publish in book form a collection of the papers presented. The conference was of undoubted value in bringing together a number of people with similar interests. The interest displayed is thought to be enough to justify a journal of applied statistics, of which the industrial applications would form a strong feature. Such a journal would be welcomed in many quarters.

E. D. VAN REST

\section{CALCULATING MACHINES AND HUMAN THOUGHT}

A COLLOQUIUM on "Les Machines à Calculer" et la Pensée humaine", organized by a committee of the Centre National de la Recherche scientifique under Prof. J. Peres and Prof. L. Couffignal, was held at the Institut Blaise-Pascal, Paris, during January 8-13. As the title of the colloquium indicates, its intention was to bring about an exchange of ideas between those concerned with the mechanical imitation of certain aspects of human thought and those studying the nervous system through which human thought is mediated. It can be said at once that, in so far as the number and distinction of the company which gathered in Paris are any indication, the colloquium was a remarkable success. Of the 260 -odd members, about thirty per cent hailed from foreign countries, and more than half of these were British; but altogether eleven countries were represented. The presence of the directors of national centres for scientific research in two European countries, and of leading workers in the relevant fields in Great Britain and the United States, gives some indication of the interest aroused.

The programme was divided into three main sections. The first was devoted to descriptions of existing computing apparatus, and discussions of the engineering aspects of computer design; the second concerned itself chiefly with mathematical applica. 
tions of computers; while in the third was discussed the extent to which useful analogies might be drawn between the functions of computing elements and those of the brain. Only a representative selection from the extensive proceedings can be attempted in this article, and much of importance must be omitted.

In the first section, accounts were given of most of the current digital computing projects in European countries, including Sweden and Switzerland, where relay-type computers have been developed. Several of the American projects were also described. Perhaps the most striking general feature of current computerdesign as presented is the growing popularity of the magnetic drum. As an auxiliary store with moderate access-time, it appears among the components of most electronic computers, and at least one machine uses a drum as its high-speed storage element. The Williams storage system is also finding increasing application, with variations on the types of trace used to represent 0 and 1 . It is significant, however, that in Dr. E. W. Cannon's account of the seven machines under construction in the United States as part of the programme of the National Bureau of Standards, the emphasis was on the diversity of techniques and design parameters used; and the hope was expressed that this would provide experience leading to the choice of optimal parameters.

The pilot model of the Institut Blaise-Pascal digital computer was demonstrated by Prof. Couffignal on the first afternoon, and aroused considerable interest and some debate. It is unconventional in employing gas-diode storage elements and flip-flop registers. Stored information can be read in one mierosecond; but the writing time is much slower. The pilot model handles eight-digit numbers, using only two double-triodes for each digit.

An interesting development in the design of mechanical differential analysers was reported from Sweden by Dr. S. Ekelöf. An integrator of the wheel-and-disk type has been devised which requires no torque amplifier. In place of a single wheel, a pair of wheels is used, with differential coupling to the output shaft. The design is such that a sufficiently heavy pressure can be maintained on the contact surfaces to give adequate torque without amplification, both wheels being in rotation even when the net output is zero. The resulting simplicity and convenient layout of the complete analyser attracted much attention.

Reference was made in discussion to the recent development in Great Britain of ultra-high-speed electronic-analogue techniques employing three- and four-dimensional cathode-ray tube displays, whereby solution-rates of 10,000 per sec. become practicable. A number of elegant applications of other analogue devices such as resistance-networks and electrolytic tanks were also described.

The second section, like the first, included several valuable papers of rather a specialized nature. Among those of more general interest, however, that of Dr. A. van Wijngaarden on rounding-off errors in systematic calculations aired a subject which is of increasing importance now that higher speed encourages the undertaking of ever-longer calculations. He showed, in particular, that the treatment of rounding-off errors as random quantities can sometimes lead to surprising anomalies, which can only be avoided by a more careful analysis.

Dr. M. V. Wilkes's paper on operational experience of the electronic delay storage automatic calculator (EDSAC) also aroused much interest, by its treat- ment of problems of organization associated particu. larly with the employment of a computer by a number of different users. It was generally felt that a greater proportion of thought should now be devoted to such operational aspects of computation, and to the design of suitable problems to enable the highest efficiency to be extracted from a computer.

Of equally general interest was Dr. H. Aiken's discussion of an operational symbolism to enable the block-diagram of a computing system to be deduced directly from the specification of the problem which it must solve. In its simplest form the symbolism appears to neglect such factors as time-delay; but in principle it is possible by its use to determine the 'minimal circuits' necessary to fulfil any given function.

The third section made its transition to the discussion of neurophysiology through an exhibition of a number of most entertaining toys, designed to illustrate the possibility of simulating different animal functions mechanically. From the early and essentially non-retroactive chess-player and other devices of L. Torres-Quevedo, the members of the colloquium were led to the characteristically retroactive "mech. anical tortoise" of Dr. W. Grey-Walter, which has been made to show a form of controlled phototropism and several other suggestive reactions by the ingenious exploitation of only two valves. Dr. W. R. Ashby's "Homeostat" illustrated a further step towards the resilience of animal life, by the provision of means for altering circuit connexions as well as feedback-currents.

Notable among succeeding papers were the American contributions from Dr. W. S. McCulloch on some of the differences between calculating machines and brains, Dr. N. Wiener on the mathematical identification of Gestalt or form, and Dr. Lorente de No on recent discoveries concerning the mechanisms of facilitation and inhibition of conduction in nerve fibres.

In other papers and in the succeeding discussion the field was further widened to include questions of a semi-metaphysical nature. The possibility that a machine might have a consciousness was hotly debated for some time, though to the writer it appeared that discussion was largely vitiated by the human habit of confusing complementarity with exclusion. This preference for black-and-white bedevils many inquiries of this nature, though the impropriety of begging the question of complementarity has been well enough demonstrated in other fields.

Among the more general issues raised in discussion, perhaps the greatest interest was aroused by the tender topic of terminology. In the field of computation the position was felt by many, particularly in non-English-speaking countries which had adopted British and American terms, to be chaotic. A French proposal that an international committee be set up to agree, if possible, on standard usage received a large measure of support. But leading voices could be heard in opposition; and Brigadier G. H. Hinds, of the British Ministry of Supply, observed that even in a single country in his recent experience it had not proved practicable to secure agreement on nomenclature in a related field. Prof. Couffignal, however, seemed more optimistic at least with regard to France, and further explorations of the question are likely.

The chief value of a conference of this kind is often not evident until afterwards. It would appear 
that little of the synthesis suggested by the title was achieved, many of the papers being presented as isolated units which made no gestures of recognition to their context; and when human thought was nominally the subject, it was, perhaps, too often only human logic which was discussed. Undoubtedly, however, in the informal contacts which were estab. lished, as well as in the formal exchange of information, a valuable preparatory contribution has been made towards a deeper analysis of the processes mediating human thought.

D. M. MACKAY

\section{CO-ORDINATION CHEMISTRY}

A SYMPOSIUM on co-ordination chemistry, at which there was an attendance of forty, was held at the Butterwick Research Laboratories of Imperial Chemical Industries, Ltd,, at Welwyn during September 21-22, 1950. The chairmen were Dr. J. Chatt (first day) and Dr. F. G. Mann (second day). The programme for the first day was concluded by a dinner and social evening, which provided an opportunity for an informal exchange of views. The guests were welcomed by Mr. M. T. Sampson, and Prof. N. V. Sidgwick opened the symposium with an account of the history of the subject up to about 1925.

Dr. F. G. Mann (Cambridge) discussed the complex derivatives of the tertiary phosphines and arsines with mercury and cadmium halides. The mercury complexes fall into five classes : (1) $\left[\left(R_{3} \mathrm{As}\right)_{2} \mathrm{HgX} X_{2}\right]$; (2) $\left[\left(R_{3} \mathrm{As}\right)_{2}\left(\mathrm{HgX}_{2}\right)_{2}\right]$; (3) $\left[\left(R_{3} \mathrm{As}\right)_{2}\left(\mathrm{Hg} X_{2}\right)_{3}\right]$; (4) $\left[\left(R_{3} \mathrm{As}\right)_{2}(\mathrm{HgX})_{4}\right] ;$ (5) $\left[\left(R_{3} \mathrm{As}\right)_{3}\left(\mathrm{Hg} X_{2}\right)_{2}\right]$. Cadmium also forms compounds similar to those in classes (1), (2) and (5). The structures of (4) and (5) are unknown. (I) has undoubtedly a simple tetrahedral structure and (2) the bridged structure. Certain compounds of class (3) occur in white and yellow forms. X-ray examination of the white form suggests that it consists of molecules of class (2) alternating with simple $\mathrm{HgX}_{2}$ molecules, the complete arrangement providing a centre of symmetry. The yellow form has no centre of symmetry.

Prof. G. Schwarzenbach (Zurich) followed with a paper on the stability constants of chelate complexes in aqueous solutions. Bjerrum has shown that simple ligands are added on to metal ions one at a time with gradual falling-off in strength of attachment with each addition. The donor groups of a polydentate ligand are attached simultaneously; if several polydentate ligands are attached, each is much less strongly bound than the last. Prof. Schwarzenbach demonstrated that this simplifies the calculation of the equilibrium constants. It was shown that the geometry of the organic polydentate ligand and the stereochemistry of the metal ion affect the stability of the complex compound. These considerations render it probable that ligands capable of strong binding to any metal cation can be synthesized.

The stability of co-ordination compounds and the varying strengths of metal-ligand bonds was also discussed by Dr. H. Irving (Oxford). In the attach. ment of ethylenediamine to cobalt, nickel, copper and zinc, the entropy changes are relatively small, and if this is generally true the equilibrium constant for the successive stages in the formation of coordination compounds will serve as a measure of relative bond-strengths. The general order of stabilities of the divalent transition ion complexes was shown to be as follows :

$$
\mathrm{Mn}<\mathrm{Fe}<\mathrm{Co}<\mathrm{Ni}<\mathrm{Cu}>\mathrm{Zn} \text {. }
$$

Departures from this order are probably due to steric factors or a change in the bond orbitals used in bond formation.

Dr. R. S. Nyholm (University College, London) described the complexes of iron, cobalt, nickel and copper with o-phenylenebis (dimethylarsine) $(=D)$, an exceptionally strong chelating agent. Magnetic susceptibilities of these complexes showed that the metal-ligand bonds are covalent. Univalent copper gives tetrahedral complexes $\left[\mathrm{Cu} D_{2}\right] \mathrm{X}$ and $\left[\mathrm{Cu} D_{2}\right]$ $\left[\mathrm{Cu} X_{2}\right]$; bivalent iron, octahedral $\left[\mathrm{Fe} D_{2} X_{2}\right]$; and bivalent cobalt and nickel, planar $\left[\mathrm{Ni}_{2} D_{2} X_{2}\right.$ and $\left[\mathrm{Co} D_{2}\right] X_{2}$. Octahedral tervalent complexes of iron, cobalt and nickel were also described, for example, $\left[\mathrm{Fe} D_{2} X_{2}\right] X^{-}$.

In discussing the co-ordination of olefins to platinous salts, Dr. J. Chatt (Butterwick Research Laboratories) briefly explained why he considered none of the structures previously proposed to be satisfactory. Evidence was presented that olefin complex formation probably involves a filled $d$-orbital of the metal atom in the manner suggested by Pauling for the carbonyls. For this bonding the ligand must have both a lone pair for donation to the metal (forming a $\sigma$-bond) and a vacant orbital to receive electrons from a $d$-orbital of the metal (forming a $\pi$-bond). Ethylene fits into this scheme if its com. plexes are ethylidene complexes, for example, $\mathrm{K}\left[\mathrm{CH}_{3} \mathrm{CH}=\mathrm{PtCl}_{3}\right]$, and the known reactions of olefin platinous complexes were explained in terms of this structure.

Dr. R. G. Wilkins (Butterwick Research Laboratories) described his experiments to determine the position of equilibrium between cis - and trans. $\left(\left(n-\mathrm{C}_{3} \mathrm{H}_{7}\right)_{3} M\right)_{2} \mathrm{PtCl}_{2}(M=\mathrm{P}, \mathrm{As}$ and $\mathrm{Sb})$. The course of the isomerization was followed by measuring the change in dielectric constant of their benzene solutions. Whereas the arsenic and antimony complexes isomerize spontaneously, it was found that the equilibrium is labile in the phosphorus series only in the presence of a trace of added $\left(n-\mathrm{C}_{3} \mathrm{H}_{7}\right)_{3} \mathrm{P}$. Evidence was presented that the former complexes produced the catalyst $\left(n-\mathrm{C}_{3} \mathrm{H}_{7}\right)_{3} M$ by their own dissociation. Preliminary experiments indicated values of $K[=[$ trans $] /[$ cis $]]$ at $25^{\circ}$ C. to be $30 \quad(M=\mathrm{P}), \mathbf{5 5}$ $(M=\mathrm{As})$ and $3.5(M=\mathrm{Sb})$.

Some new five-covalent complexes of nickel and cobalt, $\left[\mathrm{NiBr}_{3}\left(\mathrm{PEt}_{3}\right)_{2}\right]$ and $\left[\mathrm{CoCl}_{3}\left(\mathrm{PEt}_{3}\right)_{2}\right]$, were described by Prof. K. A. Jensen (Copenhagen), who demonstrated the striking colour change which occurs when red $\left[\mathrm{NiBr}_{2}\left(\mathrm{PEt}_{3}\right)_{2}\right]$ is brominated to dark green $\left[\mathrm{NiBr}_{3}\left(\mathrm{PEt}_{3}\right)_{2}\right]$. Their magnetic susceptibilities and dipole moments indicate that they have the configuration of a square pyramid with the metal atom in the centre of the base, a halogen atom at the apex and the remaining groups at the corners of the base in trans configuration. Prof. Jensen has also found an unstable complex of trivalent nickel with dimethylglyoxime $\left(D \mathrm{H}_{2}\right)$, this being $\mathrm{Ni}(D \mathrm{H})_{2} \mathrm{Br}_{3}$, which by analogy with the above complex is assumed to have $\mathrm{a} \mathrm{Br}_{3}$ group attaiched to one side of the square $\mathrm{Ni}(D \mathrm{H})_{2}$ complex.

In discussing the significance of $d$-orbital hybridization in co-ordination compounds from the point of view of quantum mechanics, L. E. Orgel (Oxford) showed that no accurate treatment is at present possible, but that the use of the overlap integral 